\title{
A new species of Hyphessobrycon (Characiformes: Characidae) from río Portuguesa, río Orinoco basin, Venezuela
}

\author{
RICARDO C. BENINE ${ }^{1} \&$ GUILHERME A. M. LOPES ${ }^{1,2}$ \\ ${ }^{1}$ Laboratório de Biologia e Genética de Peixes, Departamento de Morfologia, IBB-UNESP Campus de Botucatu, Botucatu, SP, 18618 - \\ 000,Brazil.E-mail: rbenine@ibb.unesp.br. \\ ${ }^{2}$ Programa de Pós-Gaduação em Ciências Biológicas, área de Zoologia, IBB-UNESP, Campus de Botucatu, SP, 18618-000, Brazil
}

\begin{abstract}
A new species of Hyphessobrycon is described from tributaries of the río Portuguesa, río Orinoco Basin, Venezuela. The new species is diagnosed from congeners by the presence of two large hooks on each side of the anal fin in adult males (processes of last unbranched and first branched anal-fin rays), distal third of caudal-fin black except for its distal tips (which are hyaline), anal-fin rays v,19-21, and dorsal-fin rays ii,8. Comments on its generic status and putative relationships are provided.
\end{abstract}

Key words: Neotropical region, systematics, taxonomy, Hyphessobrycon diancistrus

\section{Introduction}

Almost the totality of the small-sized genera of Characidae were originally defined by different combinations of characters including the number of premaxillary tooth rows, number of teeth in the inner premaxillary tooth row, completeness of lateral-line, caudal-fin squamation, etc. (see Eigenmann, 1917; Géry, 1977). The employment of such character combinations, allied to the lack of comprehensive phylogenetic analyses, produced morphologically diverse and, most likely, non-monophyletic genera. Consequently, the genus Hyphessobrycon, presently with more than one hundred species, is one of the most specious genera in the Characidae, and is widely distributed in Neotropical river basins (Lima et al., 2003; Bertaco et al., 2007).

Hyphessobrycon was described by Durbin (in Eigenmann, 1908) as a subgenus of Hemigrammus, from which it was distinguished by the absence of a sheath of scales covering the base of caudal fin. Currently allocated as incertae sedis in Characidae (see Lima et al., 2003), Hyphessobrycon has not been systematically studied since the monograph of Géry (1977). This author, mainly based on the revision presented by Ellis (in Eigenmann, 1918), defined this genus by the presence of premaxillary teeth in two rows (with the inner row presenting five or more teeth), the absence of a scaly sheath covering the caudal-fin lobes, and by having an incomplete lateral line.

Examination of the fish collection of the National Museum of Natural History, Smithsonian Institution, revealed an interesting characid with a pair of large bony hooks on each side of the anal fin, which better conforms to the traditional definition of the genus Hyphessobrycon.

\section{Material and methods}

The examined material in this study is deposited in the Laboratório de Genética e Biologia de Peixes (LBP), IBB-UNESP, Laboratório de Ictiologia de Ribeirão Preto (LIRP), FFCLRP-USP, Ribeirão Preto, SP, Museu 